\title{
Determination of soil stiffness parameters at a deep excavation construction site in Kenny Hill Formation
}

\author{
Law Kim Hing , Siti Zulaikha Othman , Roslan Hashim , Zubaidah Ismail
}

The demand for underground space such as deep basement

car-park, road and railway tunnels has increased

substantially in highly urbanized areas due to scarcity of

the land. A major concern in these developments is the

ability of the geotechnical engineers to predict accurately

the wall and ground movements associated with the construction

activities during the design stage. Nowadays,

numerical analysis such as finite element method (FEM)

has been assuming an increasingly important role in the

prediction of ground and wall deformations as highlighted

by Lee et al. [1].

A general overview of the Kuala Lumpur and Ipoh geological

settings is given by Tan [2] where the engineering

geologic problems in these two cities were discussed. Several

studies in the past have been conducted to examine

the soil parameters like stiffness. Tests for the stiffness of

soil at very small strain were conducted in a hydraulic

tri-axial cell fitted with bender elements and with local

axial gauges for characterizing the non-linear stress-strain

behavior of soil for monotonic loading required for analyses

of the dynamic and small strain cyclic loading of soils was

studied by Viggiani and Atkinson [3]. Simple expressions

were obtained which described the variation of strain in

terms of the current stress and over consolidation ratio.

The parameters in these expressions were found to depend

on plasticity index. The influence of layered soil in soil-

structure interaction was also estimated. The method offers

a practical method that does not require complex calculations.

Another simple and practical method for estimating

the horizontal dynamic stiffness of a rigid foundation on

the surface of multi-layered soil was proposed by Nakamura

[4]. In this method, waves propagating in the soil are

traced using the conception of the cone model, and the

impulse response function can be calculated directly and

easily in the time domain with a good degree of accuracy. 
Lipin' ski and Wdowska [5] predicted the soil stiffness with

a focus on Quaternary heavy over-consolidated stiff sandy

clay. Series of tri-axial tests on reconstituted and natural

material were carried out which provided data for setting up formula for calculation of Young's modulus in a wide

range of strain $10-2 / 1.0 \%$. A series of tri-axial tests was also

conducted by Powrie et al. [6] on samples of speswhite kaolin,

to investigate the stress-strain relations appropriate to

diaphragm walls in clay. The results of the tests highlight

the influence of the recent stress history on the behavior

of the soil. In particular, the recent stress history imposed

during wall installation was found to have significant effect

on the stiffness of the soil during the subsequent excavation

stage. Although the pre-excavation stress state of the soil

may be closer to the passive than the active condition, the

reversal in the direction of the stress path at the start of

the excavation stage means that the response of the soil

behind the wall will probably be very stiff. Shafiee et al. [7]

conducted an experimental study investigating the prefailure

and failure characteristics of compacted sand-clay

mixtures under monotonic compression and extension

loading paths. Results revealed that pore pressure, secant

modulus, undrained shear strength and angle of shearing

resistance increase when sand content was raised in both

compression and extension. It was also found that the

tested materials were over-consolidated by the fact that

normalized shear strength depends on initial confining

stress.

The fiber Bragg grating (FBG) sensor has been widely

used in the measurement of temperatures and moisture

[8-10]. Jackson et al. [11] examined the feasibility of using

inexpensive wireless nanotechnology based devices for

the field measurement of soil temperature and moisture.

In their study, the design, validation, and application of a

new flexible fiber Bragg grating (FBG) sensing beam are presented

for effectively measuring dynamic lateral displacements

inside soil mass in a shaking table test. The dynamic

lateral displacements at different depths of the soil mass

in the shaking table box throughout time history are calculated

by differential and integral methods Xu et al. [12].

In the past, the performance of deep excavations in Kenny

Hill Formation was mainly evaluated using 2D finiteelement

back-analyses as exemplified by studies by Liew

and Gan [13], Sofiana and Hooi [14] and Tan et al. [15].

Approximation is commonly needed in $2 \mathrm{D}$ numerical model

to represent the real situations and this could lead to 
uncertainty in the interpretation and validity of the results as shown by Simpson et al. [16]. The correlation of soil stiffness parameters with standard penetration test (SPT) $\mathrm{N}$ value, which was calibrated based on $2 \mathrm{D}$ back-analyses results may not be representative of actual condition at the site. Field data clearly indicated that the stiffening effect of corners lead to much smaller wall and ground movements at the corners as compared to that measured near the middle of the excavation wall as shown by Lee et al. [17], Ou and Shiau [18] and Ou et al. [19]. In this case, when back analyses were performed to calibrate the $2 \mathrm{D}$ model, the soil stiffness would have to be increased in order to match the observed wall deflection. Therefore, 3D geometrical or corner effect needs to be considered when back-analyses were performed in order to get a meaningful empirical correlation to be adopted in the future in same soil conditions.

A common problem in the analysis of deep excavation in residual soils is the soil tests data often limited or low quality due to the difficulty in obtaining undisturbed in situ soil samples. Very often, acceptable data on strength properties of soil could be obtained through laboratory tests but not on its modulus value. Therefore, information from back-analyses of the Young's modulus based on local case histories, if available, are often very useful for engineering judgment in the estimation.

This study examined the soil stiffness parameters for a deep excavation supported by diaphragm wall in weathered residual soils of Kenny Hill Formation. An elastoplastic isotropic Hardening Soil (HS) model following Schanz et al. [20], as implemented in commercial finite element program PLAXIS, was employed in this study. The objective is to provide data for the determination of horizontal displacements which can also be generally applied to other excavation works in soil conditions similar to the Kenny Hill Formation.

Material and methods

The study project is located at Lebuh Ampang, Kuala Lumpur city center. It is a 24-storey office building with 5 levels of basement car-park. The construction of basement involved $18.5 \mathrm{~m}$ deep of excavation, approximately $30 \mathrm{~m}$ wide and $35 \mathrm{~m}$ long, in weathered residual soils of Kenny Hill Formation. The excavations were performed using the bottom-up method. The diaphragm wall of 
$23 \mathrm{~m}$ deep and $0.8 \mathrm{~m}$ thick was supported by three levels

of $\mathrm{H}$-section steel struts with $3.5 \mathrm{~m}$ horizontal spacing on

average. A double steel section was used for 2 nd and 3 rd

layers strut to provide sufficient resistance against high

horizontal earth pressures at these levels. At the contact

point between the strut and diaphragm wall, I-section

walers supported by angle brackets were installed to provide

better load transfer between the retaining wall and

struts.

The ground condition at the site generally consists of

residual soils and weathered rocks of the Kenny Hill

Formation. This formation is also referred by Komoo [21]

as meta-sedimentary, considering that the sedimentary

rocks (e.g. sandstone, siltstone) have been partly metamorphosed

into quartzite and phyllite. The weathering process

of the rock material which is rather complex have been

described by Raj [22].

The soil profile at this project site consists of an upper

$6 \mathrm{~m}$ of recent alluvium underlined by Grade IV to VI residual

soils of Kenny Hill Formation up to depths of about

$30 \mathrm{~m}$. Highly fractured and weathered Siltstone with Rock

Quality Designation (RQD) of $0 \%$ is encountered beyond

30 mdepth. Grading analysis revealed that the residual soil

mainly consists of sandy silt and clayey silt material. Standard

penetration test (SPT) blow counts were low in the

alluvium layer but increases beyond 50 blows $/ 300 \mathrm{~mm}$

from depth exceeding $10.5 \mathrm{~m}$. The high SPT- $\mathrm{N}$ values

exceeding 150 blows $/ 300 \mathrm{~mm}$ were probably due to the

presence of quartz veins or phyllite fragments encountered

in the boreholes. The bulk density of residual soil layers are

generally ranged from $19 \mathrm{kN} / \mathrm{m}_{3}$ to $22 \mathrm{kN} / \mathrm{m}_{3}$ with depth.

The moisture content of residual soil layers are close to

plastic limit with plasticity index generally lying in between $15 \%$ and $30 \%$. The groundwater table is located at

depth of $4.5 \mathrm{~m}$ below ground surface.

The movements of the diaphragm wall, the ground and

the adjacent buildings were monitored during excavation

using standard monitoring devices. Fig. 1 shows the excavation

site along with the instruments for monitoring locations.

Eight inclinometer casings (I-1 to I-8) were installed

inside $800 \mathrm{~mm}$ thick diaphragm wall to monitor the lateral

displacements of diaphragm wall. All the inclinometer casings

were installed to a depth of 3 mbelow diaphragm wall

toe level, so that the toe movement of the diaphragm wall

can be measured. 
Six water standpipes (P-1 to P-6) were also installed

outside the excavation area to monitor the fluctuation

of groundwater table during the entire excavation

process.

Mesh and boundary conditions

The excavation geometry of the case history was carried

out for a plan area of approximately $30 \mathrm{~m}$ by $35 \mathrm{~m}$. The

ratio of excavation length to width is about 1.2 suggesting

that a plane strain 2D model may not be appropriate due to

corner effect of the excavation [6-8]. The numerical back

analyses of this case history have therefore been conducted

by 3D finite element analyses using the program PLAXIS

3D FOUNDATION Version 2.2.

Fig. 2 shows the finite element mesh adopted in the

numerical back analyses. The side boundaries of the mesh

are prevented from movement in the horizontal plane but

are free to move vertically and the bottom boundary of the

mesh is fully fixed. The $0.8 \mathrm{~m}$ thick diaphragm wall was

modeled with isotropic linear elastic plate elements. Soil

elements are 15-node wedge elements which are created

by projection of 2D, 6-node triangular elements. Supporting

steel struts were modeled with isotropic linear elastic

beam elements. The diaphragm wall was assumed to be

"wished-in-place". The installation effect of diaphragm

wall was not considered.

Full text available at :

http://ac.els-cdn.com/S0263224113004685/1-s2.0-S0263224113004685-main.pdf?_tid=2a814a02-66e4-11e3-

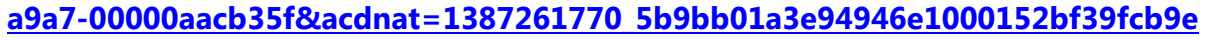

http://www.sciencedirect.com/science/article/pii/S0263224113004685 